\title{
Global and Canadian population and beyond: Introduction
}

\author{
Susan A. McDaniel*
}

Global population - trends, patterns, and challenges - is increasingly of interest to demographers, geographers, political scientists, environmentalists, and many others. The population of the world has recently reached 7 billion. The United States Census Bureau (US Census Bureau 2014) estimates that the 7 billion number was reached on March 12, 2012, while the United Nations Population Fund (UN Population Fund 2011) claims that it was reached on October 31, 2011. It hardly matters and is impossible to estimate precisely when a milestone number is crossed. What does matter is that the global population is growing - and growing rapidly. United Nations projections predict that the 8 billion mark will be in 2025 (UN Population Fund 2014). Population growth across the world is also uneven.

The United Nations Population Fund sees crossing the threshold to 7 billion as both an opportunity and a challenge. As both opportunity and challenge, they note implications for environmental sustainability, urbanization, access to health services, and youth empowerment. The good news is that globally more people are living longer, healthier lives with smaller families. The less good news is that global inequalities continue to widen, and global cooperation on key present and future challenges remains spotty and uncertain.

It is clearly better to be alive today for most of those in the world than it ever has been in the past-with the exception, of course, of war zones and places experiencing extreme events. Wellbeing and life expectancy are generally growing across the world, with the notable exceptions of Russia, where male life expectancy has dropped since the demise of the Soviet Union, and sub-Saharan Africa, where the HIV/AIDS pandemic has reduced overall life expectancy in several countries. In Russia, life expectancy fell precipitously from 1990 to 1994, when it was 57 years, then recovered slightly to its current 64.3 years, the lowest in the developed world (Leon 2011).

Moreover, inequalities both within and across countries and regions of the world are, for the most part, growing. Nearly all the population growth leading to the 7 billion in 2011/12 took place in less developed countries. Although the total fertility rate in the world has sharply declined, and fertility rates in most countries have also decreased, disparities remain. Sub-Saharan countries in Africa still have high family sizes, as do some countries in the Middle East. And many countries in Europe (Germany, Spain, and Italy, in particular), and East Asia (Japan, Taiwan, South Korea, and Singapore), as well as Canada in North America, have concerns about fertility rates being too low, and thus populations that are ageing.

Inequalities also are sharpening among economies, affecting country capacities to provide decent and equitable quality of life for their citizens. In the poorest countries, extreme poverty, food insecur-

* Susan A. McDaniel, PhD, FRSC. Director, Prentice Institute \& Canada Research Chair in Global Population \& Life Course, Prentice Research Chair \& Professor of Sociology, University of Lethbridge, Suite L1184 (Library Information Network Centre), 4401 University Drive West, Lethbridge AB Canada T1K 3M4. Email: susan.mcdaniel@uleth.ca. 
ity, inequality, high death rates, and high birth rates are linked in a vicious cycle. It is now well understood that this cycle can be broken by serious investment in education and healthcare for women and girls. This investment is hard to come by, however, as "development funds" from the more developed countries have been reduced, while the governments of poor countries find it difficult to appropriate the funds needed. The global financial crisis of 2008+ exacerbated an already trenchant challenge by raising food prices and further reducing assistance programs as well as charitable donations to less well-off countries. And climate change may derail the attempts of poorer countries to climb up, by disrupting crop yields and endangering communities, particularly those on coasts and in low-lying areas.

On the positive side, investment in education and health, as many East Asian countries did in the early 1960s, can result in a "demographic dividend." This is when family sizes decline and labour force groups expand, leading to a productivity spurt. This has been found to be a factor in East Asian economic success stories (see UN Population Fund 2014). To be effective, however, the demographic dividend must exist in parallel with a vibrant economy that can accommodate a larger working population. Without that vibrant economy, having larger numbers of youth in populations can result in political unrest.

Among the most significant of global population challenges are those related to migration. It is anticipated that almost all of the global population growth in coming decades will either occur in cities or will be absorbed by cities in rural to urban migration. The vast majority of global citiesparticularly those in poorer countries but also those in more developed countries-are ill-prepared for such growth. In whatever part of the world they are found, cities tend to concentrate poverty. They can also make poverty mitigation easier, due to their settlement density and vibrancy. Cities, particularly those that grow rapidly without attention to sanitation expansion and needed infrastructure, can produce serious environmental challenges. Megacities can accompany and accommodate solid economic growth, but they can also be magnets for the disenfranchised, who have no choice but to live on the edges in rapidly growing slums.

Global migration is an increasing challenge as well. People tend to want to move where they see opportunities for themselves and their families. This puts enormous pressure on countries with dynamic economies, and real or perceived opportunities for work and social mobility, to develop policies that affect immigrants. Settler societies such as Canada, Australia, and the United States work diligently to change and adjust their immigration policies. Other countries that are less accustomed to new arrivals, such as many European countries, have more trouble in making the necessary adjustments. This can, and has, led to serious confrontations over newcomers, at times resulting in political and criminal activities that are decidedly anti-immigrant.

Refugees are still another global population challenge, in a world with huge refugee camps as a result of war-witness Syria at present. Refugees can also come from situations of stark deprivation, such as the leaky ships coming from North Africa and attempting to make their way to Italy and into Europe, or escaping horrific violence in their homelands-for example, those in Rwanda and Somalia who now find themselves in the Central African Republic. Refugees pose particular challenges to developed countries in that it is immensely difficult to sort out who is a genuine refugee, and to distinguish between the smugglers and those who are genuinely fleeing. What has happened of late is that refugees are increasingly being lumped into various "illegitimate" categories, and their claims are not being considered. If and when they are deported, it is not clear what fate awaits them.

Still another area of global population interest is health—specifically, population health. This is a growing area of research worldwide, with interest in how income and other inequalities play out 
on the health of populations. Stress, mental health, obesity, and a plethora of other health issues are being examined in global and country-specific contexts. Availability of new data, particularly longitudinal data and data linkage, enables new insights into how society and social factors get "under our skins” (McDaniel 2013).

The Prentice Institute for Global Population and Economy at the University of Lethbridge is a unique educational and research institute, whose mandate includes studying much of the above and more. The Prentice Institute, of which the major authors of articles in this special issue are Research Affiliates, was created in 2006 with an initial endowment of $\$ 8.5$ million from the awardwinning agrologist and agri-business entrepreneur, Dr. John Prentice (that donation has since been augmented). The Prentice Institute became fully operational in mid-2009 with the appointment of its inaugural director, Dr. Susan McDaniel. In addition to serving as director, she holds the Prentice Research Chair in Global Population and Economy, and subsequently, in 2011, the Tier 1 Canada Research Chair in Global Population and Life Course. She is also a Professor of Sociology.

The mandate of the Prentice Institute is to:

- conduct, integrate, and stimulate research pertinent to the dynamics of Canadian and global population and its impact on economic well-being through migration, culture, trade, and natural resource availability, including water;

- contribute freely to public dissemination and to provide knowledge that will better enable informed decisions by individuals, governments, and corporations regarding issues of global population;

- seek to understand the challenges that are causing long-term changes in human and economic environments, with particular attention to the role human actions play in influencing those outcomes;

- contribute actively to the education and training of students.

The Prentice Institute is multi-disciplinary in both its research and education/training of students, including MA and PhD students as well as undergraduates. We also have an active group of post-doctoral fellows. Prentice Institute Research Affiliates come from every faculty at the University of Lethbridge, and from across Canada and around the world. Our Research Affiliates now number 34 leading national and international experts, who seek to understand major challenges in the world that fall within our mandate, including environmental change, food security, population change (including immigration and migration), labour and skills distribution and projections, ageing populations, health challenges, growing income inequalities, water and agricultural scarcity, poverty, and more. In each of these broad topics, researchers at the Prentice Institute have:

- undertaken ongoing research projects, many grant-funded;

- published books, articles and public media pieces;

- given talks both academic and public, locally as well as nationally and internationally;

- engaged with students in classrooms, in supervisory roles, and as junior researchers.

This special Prentice Institute issue of Canadian Studies in Population showcases a select sample of the research being done by Prentice researchers. It is broad and encompassing in its overall reach, giving readers, we hope, a sense of the breadth and depth of research at the Prentice Institute. The paper by Germain Boco looks at sex differentials in childhood mortality across thirty countries in sub-Saharan Africa. Although excess male childhood mortality in much of Africa has long been a known problem, Boco's research adds two new dimensions: (1) he takes a serious look at biological, 
social, and environmental factors together as possible contributors to excess male mortality; and (2) he compares and contrasts thirty different countries. His findings for most of the countries in the analysis - that individual-level and community-level factors do not explain persistent sex differences in childhood mortality-hint that biological factors may be at root.

The paper by Alexander Darku takes an innovative look at the relationship between income inequality and savings rates. The hypothesis he entertains is that as income inequalities increase, those at the top tend to spend more, inducing those at other steps down in the distribution to do the same, thus reducing rates of savings. His findings, although not unequivocal across all provinces, are generally consistent with this hypothesis.

Michael Haan and colleagues focus on the topic of employment-motivated geographic migration. Although much is said on this issue in speculative media columns or in policy circles, insufficient empirical research has been done. The research by Haan et al. relies on the 2006 Census of Canada confidential master file to create statistical portraits of employment-related geographical mobility. Their goal is to understand the full gamut of home-to-work commutes/migration-from none (those who work from home) to very long distance commutes across the country-and to see what characteristics differentiate these groups. Long-distance commuters are found to be differentially young men in Newfoundland and Labrador who work in the oil patch in Alberta. Perplexing questions, of course, are raised by this research. How do these workers decide to commute such long distances to work, and what kinds of challenges or opportunities do these patterns create? Does policy play a role in encouraging or discouraging labour mobility?

The paper by Richard Mueller considers a topic not much examined in contemporary population research: the wage differentials of same-sex versus different-sex couples in Canada. As we know, gay marriage has been legal across Canada since 2005, so [civil] discrimination no longer exists in the choice to legally marry or not. Yet, little is known about earnings differentials between gay/ lesbian couples and heterosexual couples. Relying on five cycles of the General Social Survey (20062010), Mueller finds that gay couples have earnings that are essentially the same as the earnings of heterosexual couples. Lesbian couples, on the other hand, earn significantly more than heterosexual couples. He notes, based on the sparse previous evidence, that the wage penalty for gay men may be diminishing over time. The finding for lesbian couples is more surprising, and indicates the need for additional research on the topic.

William Ramp's paper is a conceptual excursus on definitions, and the implications of descriptive word usage about food security as to how we see it and approach it practically. He argues that responses to the challenges of global food security necessitate double work: to interrogate the issues, and to reflect on the terms of that interrogation. This analysis is productively infused with sociological theory, opening a wide and welcome barn door to reflecting on what food security means in shifting global contexts of population, consumption, climate change, environmental degradation, water scarcity, and the geopolitics of globalization. Ramp's work could form the basis of multiple interdisciplinary research programs.

The last paper in this special issue is by Wei Xu and colleagues. Their attention is devoted to the question of regional economic differentiation effects on labour migration in China - an important policy issue with the rapid development, until recently, of the Chinese economy. Economic development in such a rapidly changing society is bound to be uneven. Based on analysis of data from four case study cities in Fujian province, they find that migrant labour markets and their earning determinants are geographically structured. The mechanisms determining migrant workers' earnings are largely affected by processes of regional economic change. This means that in more highly advanced 
regions, the return on human capital is greater for labour migrants, and the effects of institutional and cultural factors are weaker.

These papers, taken together, provide a brief taste of the important and wide-ranging research ongoing at the Prentice Institute for Global Population and Economy at the University of Lethbridge. In 2014, the Prentice Institute will celebrate five years of its existence. We sense that we are making a vital contribution in our research, education, and outreach mandate, towards a deeper understanding of issues related to global population and economy. Please feel free to visit us on our website: http:// www.uleth.ca/prenticeinstitute/, where more information can be found about our research and researchers, as well as podcasts of our speaker and seminar series and a wealth of data on global population and economy.

\section{References}

Leon, D. 2011. Trends in European life expectancy. International Journal of Epidemiology 40:271-277.

McDaniel, S.A. 2013. Understanding health sociologically. Current Sociology 61(5/6), published online on 13 May at http://csi.sagepub.com/content/early/2013/05/13/0011392113480471.full.pdf + html

UN Population Fund. 2011. The World at 7 Billion. http://www.unfpa.org/public/home/ sitemap/7Billion [accessed 15-03-2014]

- 2014. The World at 7 Billion: Top Issues, Fact Sheets. http://www.unfpa.org/webdav/site/ global/shared/documents/7\%20Billion/7B_fact_sheets_en.pdf [accessed 22-03-2014]

US Census Bureau. 2014. World Population Clock. http://www.census.gov/popclock/[accessed 15-032014] 